\title{
Paisagem urbana em Teresina: Implicações da distribuição ESPACIAL DA DENSIDADE POPULACIONAL
}

\author{
Amélya Djiullya Silva Terceiro ${ }^{1}$, Giovana Mira de Espindola ${ }^{2 *}$, Eduilson lívio Neves da Costa \\ CARNEIRO $^{3}$
}

\author{
${ }^{1}$ Engenheira Cartógrafa e Agrimensora, Departamento de Transportes, Centro de Tecnologia, Universidade Federal do Piaui (UFPI) \\ ${ }^{2}$ Docente do Departamento de Transportes, Centro de Tecnologia, e do Programa de Pós-Graduação em Desenvolvimento e Meio Ambiente (PRODEMAl \\ TROPEN), Universidade Federal do Piaui (UFPI) \\ ${ }^{3}$ Docente do Departamento de Informação, Ambiente, Saúde e Produção Alimentícia, Instituto Federal do Piaui (IFPI) \\ *Autora para correspondência: giovanamira@ufpi.edu.br
}

Recebido em 17 de abril de 2016. Aceito em 23 de março de 2018. Publicado em 14 de abril de 2018.

Resumo - No Brasil, a migração rural-urbana tem ocorrido prioritariamente em cidades com menos de 1 milhão de habitantes, localizadas nas regiões Centro-Oeste e Nordeste do país. A cidade de Teresina, maior cidade do estado do Piauí, é exemplo de capital que tem apresentado acelerado processo de desenvolvimento urbano nas últimas décadas. Neste contexto, o objetivo principal deste artigo é discutir a distribuição espacial da densidade populacional em Teresina, e as implicações sociais e ambientais da ocupação desordenada de seu espaço urbano. Foram usadas imagens de sensores dos satélites RapidEye, e dados do censo demográfico do Instituto Brasileiro de Geografia e Estatística (IBGE). O mapa de uso do solo foi combinado aos dados populacionais agregados em setores censitários, de modo a fornecer novos subsídios ao planejamento urbano da cidade. Os resultados indicam que a densidade urbana em Teresina varia consideravelmente, e que as regiões periféricas concentram as maiores densidades, com valores distantes do padrão de 100 habitantes/ha estabelecido pela legislação municipal.

Palavras-chave: Urbanização; Cidades MédLas; Uso Do Solo; RapidEye; Plauí.

\section{Urban landscape in Teresina: IMPLICATIONS OF THE SPATIAL Distribution OF POPUlation DENSity}

Abstract - The rural-urban migration in Brazil has primarily occurred in cities with less than 1 million inhabitants in the Central-Western and Northeastern regions of the country. The city of Teresina, the largest city in the state of Piauí, is an example of a capital with an accelerated process of urban development in the last decades. In this context, the main objective of this study is to discuss the spatial distribution of population density in Teresina, and the social and environmental implications of the disordered occupation of its urban space. RapidEye satellites sensor images and Brazilian Institute of Geography and Statistics (IBGE) data were used. The map of land use was combined with the population data aggregated in census units to provide new insights into the urban planning of the city. The results indicate considerable variation of urban density in Teresina and the highest density in the peripheral regions, with values far from the standard of 100 inhabitants/ha proposed by the municipal legislation.

Keywords: Urbanization; Medium Cities; Land Use; RapidEye; Piauí.

Paisaje urbano en Teresina: Implicaciones de la distribución espacial de la densidad poblacional

Resumen - En Brasil, la migración rural-urbana ha ocurrido principalmente en ciudades con menos de 1 millón de habitantes, localizadas en las regiones Centro-Oeste y Nordeste del país. La ciudad de Teresina, mayor ciudad del estado de Piauí, es un ejemplo de capital que ha presentado un proceso acelerado de desarrollo urbano en las últimas décadas. 
En este contexto, el objetivo principal de este artículo es discutir la distribución espacial de la densidad poblacional en Teresina, y las implicaciones sociales y ambientales de la ocupación desordenada de su espacio urbano. Fueron utilizadas imágenes de sensores de los satélites RapidEye y datos del censo demográfico del Instituto Brasileño de Geografía y Estadística (IBGE). El mapa de uso del suelo fue combinado con los datos poblacionales agrupados en sectores censales, de modo que aporte herramientas que ayuden en el planeamiento urbano de la ciudad. Los resultados indican que la densidad urbana en Teresina varía considerablemente, y que las regiones periféricas concentran las mayores densidades, con valores distantes del patrón de 100 habitantes/ha establecido por la legislación municipal.

Palabras clave: Urbanización; Ciudades promedio; Uso del suelo; RapidEye; Piauí.

\section{INTRODUÇÃO}

A expansão de cidades médias no Brasil tem aumentado significativamente desde as décadas de 1980 e 1990, quando grande parte dos movimentos migratórios rurais deixaram de ser direcionados aos centros urbanos consolidados do Rio de Janeiro e São Paulo. Nos últimos anos, a concentração populacional em cidades médias tem resultado em acelerado processo de urbanização, caracterizado por elevadas taxas de crescimento econômico e populacional (Marandola Jr e Modesto 2012; Rodrigues e Veloso Filho 2013; Brenner e Schmid 2014). Pelos critérios da ONU (Organização das Nações Unidas), cidades médias são aglomerações urbanas com população entre 100 mil e 1 milhão de habitantes. São também consideradas médias as cidades que possuem localização privilegiada considerando sua centralidade, e que exercem um poder sobre os sistemas regionais ou nacionais em que estão inseridas, funcionando como polo de desenvolvimento físico, social e econômico (Wang et al. 2012; United Nations 2014).

Nas cidades médias brasileiras, as tendências de concentração urbana e as altas densidades, largamente observadas nas cidades de grande porte, ainda não chegaram a afetar de forma significativa a vida da população. Em médias aglomerações, os preços das habitações são considerados relativamente baixos, as distâncias internas ainda não são significativas, facilitando a mobilidade urbana, e o tráfego e a poluição não atingiram níveis preocupantes (Maurício e Barros 2012). Apesar do movimento rumo às cidades médias ser positivo pelo impulso que dá ao desenvolvimento destas regiões, o crescimento destes novos centros preocupa pela falta de implantação de políticas urbanas sustentáveis (Damiani 2004; Güneralp et al. 2013). Assim, a questão do rápido crescimento, que geralmente não é acompanhado por políticas de planejamento urbano a longo prazo, acaba resultando em problemas comuns já vistos em grandes metrópoles, em sua maioria vinculados às desigualdades espaciais, ao trânsito pesado e a falta de saneamento básico (Sperandelli et al. 2013; Reis Filho e Moura 2014; Limoeiro 2015).

Questionamentos mais amplos sobre a melhor forma de uma cidade crescer plena com redução de possíveis problemas e uma sustentabilidade evidente fazem parte da atualidade nacional (Wang et al. 2012; Brenner e Schmid 2014). Há recentemente grande debate a respeito da melhor organização do espaço urbano e sobre parâmetros de concentração populacional e expansão da macha urbana (Buhaug e Urdal 2013). Se por um lado, altas densidades urbanas, com maior quantidade de pessoas morando em uma determinada área, possibilitam menor deslocamento e economia na implantação de equipamentos urbanos, por outro, baixas densidades organizam melhor as áreas verdes e de lazer, com menos congestionamentos e baixa poluição (Turner et al. 2007; Seto et al. 2012). 
Segundo Espindola et al. (2017), representações espaciais de fenômenos urbanos, e de processos de produção do espaço urbano, têm cada vez mais recorrido ao uso de tecnologias como o sensoriamento remoto e o geoprocessamento (Duque et al. 2015; Li et al. 2015; MacLachlan et al. 2017). A vantagem do uso de tais conceitos e tecnologias reside em proporcionar elementos importantes e atuais, capazes de apreender o processo de expansão e consolidação da mancha urbana e de seus desdobramentos sociais (Ferreira 2007). Assim, imagens de sensores orbitais e dados espaciais de diversas fontes tornam-se ferramentas importantes no planejamento e na gestão de cidades contemporâneas (Pereira e Silva 2001; Leite e Rosa 2006).

Neste contexto insere-se a cidade de Teresina, cidade média do Nordeste brasileiro que tem apresentado elevadas taxas de urbanização nas últimas décadas, com grande incremento econômico e populacional, além de ter se tornado centro político-administrativo do Estado e polo econômico da região. A partir da década de 1970, a expansão urbana de Teresina foi motivada por importantes investimentos em infraestrutura e habitação, o que resultou na migração maciça de pessoas atraídas por melhores condições de vida na cidade. No entanto, este processo tem causado problemas urbanos sérios, derivados da insuficiência de moradias e da especulação imobiliária que tem empurrado a população de baixa renda para a ocupação de terrenos com baixos padrões urbanísticos, em geral localizados em áreas periféricas ou vulneráveis (Cruz et al. 2016; Nogueira et al. 2016; Espindola et al. 2017).

Desta forma, os impactos negativos da urbanização em Teresina são resultados de um processo histórico de ocupação deficiente em planejamento urbano. Assim, o presente artigo parte do uso de imagens dos satélites RapidEye de 2011 e dos dados censitários do Instituto Brasileiro de Geografia e Estatística (IBGE) de 2010. O objetivo principal deste artigo é descrever e mapear os usos urbanos da paisagem, estabelecendo as relações entre a densidade de áreas construídas e a distribuição espacial da população, discutindo ainda as implicações sociais e ambientais do recente processo de ocupação urbana em Teresina.

\title{
MATERial e mÉtodos
}

\author{
Área de Estudo
}

Teresina, capital do estado do Piauí, foi fundada em 16 de agosto de 1852. A cidade foi idealizada por Conselheiro Saraiva, tendo como traçado geométrico a forma de tabuleiro de xadrez com um modelo de ruas horizontais e verticais, tornando-se a primeira capital do Brasil com esta configuração (Reis Filho e Moura 2014). Teresina situa-se num ponto estratégico, entre os Rios Parnaíba e Poti, a $05^{\circ} 05^{\prime}$ de latitude sul e $42^{\circ} 48^{\prime}$ de longitude oeste, pertencendo a mesorregião Centro-Norte Piauiense (Figura 1). O município apresenta clima tropical com dois períodos distintos: um quente e úmido, entre os meses de janeiro a julho; e outro quente e seco, entre os meses de agosto a dezembro. A temperatura média é de $29^{\circ} \mathrm{C}$ com uma variação de pouco menos de $10^{\circ} \mathrm{C}$ entre o dia e a noite. A vegetação da região apresenta exemplares de Caatinga, Mata de Cocais e Cerrado, encontrando-se com frequência palmeiras de babaçuais e carnaubais (Bartholomé et al. 2002; Bartholomé e Belward 2005). A cidade é ainda importante por apresentar grandes jazidas de argila de boa qualidade, tornandose a maior fornecedora do Nordeste desta matéria-prima e de tijolos e telhas industriais. 
Figura 1 - Localização geográfica do município de Teresina.

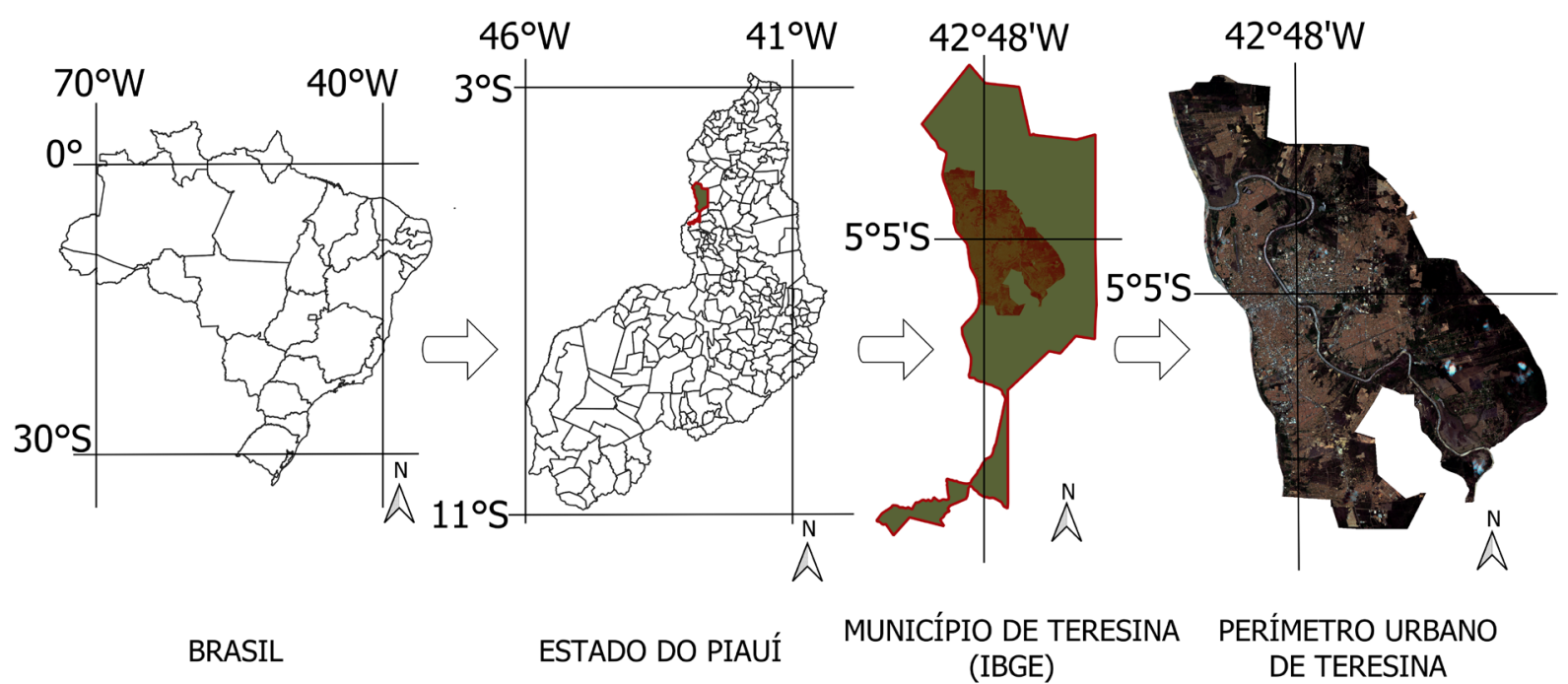

De 1970 até 1991, Teresina apresentou taxa de crescimento populacional de 5,50\% ao ano. Observase ainda que nas últimas três décadas Teresina passou por um intenso crescimento populacional, em 1980 a população não chegava a 400.000 habitantes e, em 2010 passou a 814.230 habitantes, sendo atualmente polo de processos migratórios da região Nordeste. Foi também a cidade do Nordeste onde a renda per capita mais cresceu entre os anos de 1970 e 2000, com taxa média de crescimento anual de 4,16\% ao ano. Segundo dados do IBGE (2013), o território de Teresina compreende uma área total de 1.391,98 Km² população total estimada de 844.245 habitantes em 2015, sendo que, segundo a Secretaria Municipal de Planejamento e Coordenação de Teresina, da área total do município, 17\% é considerada urbana e 83\% rural (Espindola et al. 2017).

Atualmente, a cidade é dividida em regiões administrativas denominadas Superintendências de Desenvolvimento Urbano (SDU), nomeadas conforme a Figura 2 em Centro-Norte, Leste, Sudeste e Sul, e delimitadas segundo o atual perímetro urbano, estabelecido pela Lei $\mathrm{N}^{\circ} 3.559$, de 20 de outubro de 2006. Ainda, por meio do I Plano Estrutural de Teresina, estabelecido em 1978, foi definido o padrão aceitável de densidade populacional de 100 habitantes/ha.

\section{Mapa de Uso do Solo}

O presente artigo busca investigar e mapear usos urbanos da paisagem (Pereira e Silva 2001; Leite e Rosa 2006), por meio de procedimentos metodológicos que contribuam para o planejamento urbano de Teresina. Neste trabalho, o termo 'paisagem' é entendido como 'meio', que na geografia física, é inerente à uma finalidade ecológica que integra o natural e suas alterações derivadas de ação antrópica (Bertrand 2004). Assim, a proposta metodológica faz uso de conceitos de sensoriamento remoto e de geoprocessamento, favorecendo uma representação cartográfica fiel e atualizada do território e de suas dinâmicas (Tyner 1992; Burrough e McDonnell 1998; Slocum 2009). Deste modo, foram usadas imagens dos satélites RapidEye (Boshuizen et al. 2014; Stoll et al. 2014), como insumos básicos para a elaboração do mapa de uso do solo da mancha urbana de Teresina. 
Figura 2 - Divisão administrativa de Teresina.

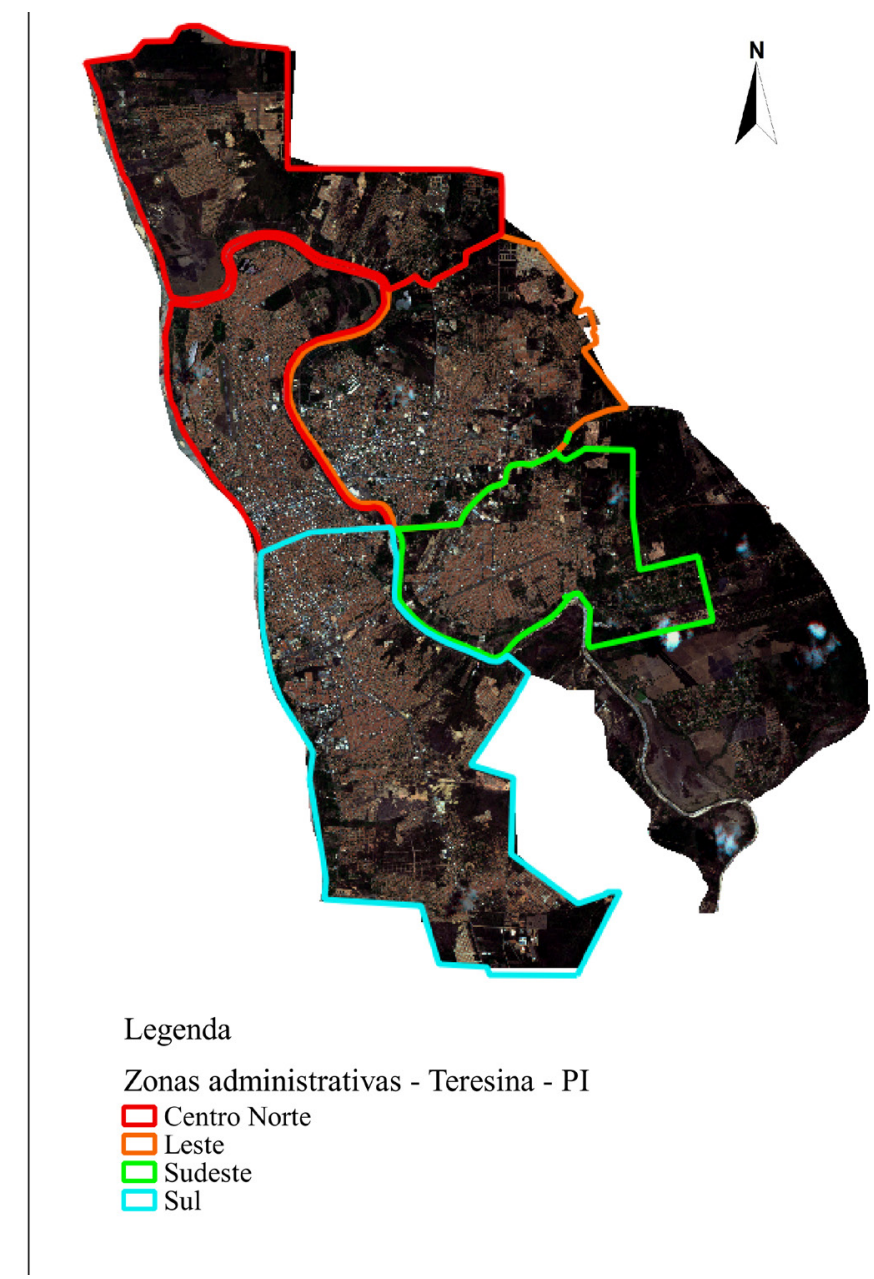

As imagens RapidEye foram escolhidas por apresentarem características espaciais, espectrais e radiométricas compatíveis com a delimitação dos alvos urbanos de interesse (Quadro 1). O sensor multiespectral a bordo dos satélites RapidEye (REIS) coleta imagens em cinco faixas espectrais que variam dos comprimentos de onda de $0,44 \mu \mathrm{m}$ a $0,85 \mu \mathrm{m}$. A resolução espacial é de 5 metros nas imagens corrigidas geometricamente, com precisão de detalhe compatível com escala 1:25.000. (Felix et al. 2009; van Rees 2014). As imagens utilizadas foram adquiridas pelo Ministério do Meio Ambiente (MMA), e disponibilizadas pelo Programa de Regularização Ambiental do Cadastro Ambiental Rural (Landau et al. 2012; Antunes et al. 2014). Para cobrir toda a área de estudo foram necessários quatro recortes de imagens, todos eles coletados em 17 de setembro de 2011.

Quadro 1 - Especificação técnica do sensor REIS (RapidEye Earth Imaging System) (Felix et al. 2009).

\begin{tabular}{|l|l|}
\hline Tipo de Sensor & Multiespectral (pushbroom imager) \\
\hline & Banda 1 (Azul): 440 -510 nm \\
& Banda 2 (Verde): 520 -590 nm \\
& Banda 3 (Vermelho): 630-685 nm \\
& Banda 4 (Red-edge): 690 - 730 nm \\
& Banda 5 (Infravermelho Próximo): 760 - 850 nm \\
\hline Resolução Espacial & $6,5 \mathrm{~m}$ (nadir) e 5 m (ortorretificada) \\
\hline Resolução Radiométrica & 12 bits \\
\hline
\end{tabular}

Assim, a fim de possibilitar uma leitura da paisagem, parte-se do mapeamento dos usos do solo como forma 
de representação cartográfica do território urbano. Com base na interpretação visual da composição colorida falsa-cor RGB-532, foram identificadas as categorias e classes temáticas de interesse descritas na Quadro 2. O mapeamento de tais classes temáticas foi realizado por classificação digital supervisionada por regiões, e para tanto, foram coletadas amostras espectrais de alvos representativos de cada classe. As curvas espectrais dos 10 alvos selecionados representativos das classes temáticas são apresentadas na Figura 3. Visualmente, percebe-se a discriminação entre cada classe analisada, apesar de uma leve semelhança entre os alvos de recursos hídricos e telhado Metálico/Cor Cinza. As demais curvas apresentam comportamento espectral característico, permitindo a separabilidade das classes de uso no processamento da classificação digital.

Quadro 2-Descrição das classes temáticas de interesse.

\begin{tabular}{|l|l|l|}
\hline \multicolumn{2}{|l|}{ Categorias/Classes Temáticas } & Descrição \\
\hline Recursos Hídricos & Rios, lagoas e lagos artificiais \\
\hline Solo Exposto & $\begin{array}{l}\text { Área que possui solo exposto (em geral, solos arenosos e desma- } \\
\text { tados) }\end{array}$ \\
\hline \multirow{4}{*}{ Vegetação } & Densa & Cobertura vegetal densa \\
\cline { 2 - 3 } & Moderada/Rasteira & Cobertura vegetal moderada, rasteira e áreas verdes \\
\hline \multirow{5}{*}{ Mancha Urbana } & Asfalto \\
\cline { 2 - 3 } & Ruas/Calçamento \\
\cline { 2 - 3 } & \multirow{4}{*}{ Telhados } & Cerâmico \\
\cline { 3 - 3 } & & Concreto/Laje \\
\cline { 3 - 3 } & Metálico/Cor Branca \\
\cline { 3 - 3 } & Metálico/Cor Cinza \\
\hline
\end{tabular}

Figura 3 - Curvas espectrais dos alvos representativos das classes temáticas de interesse.

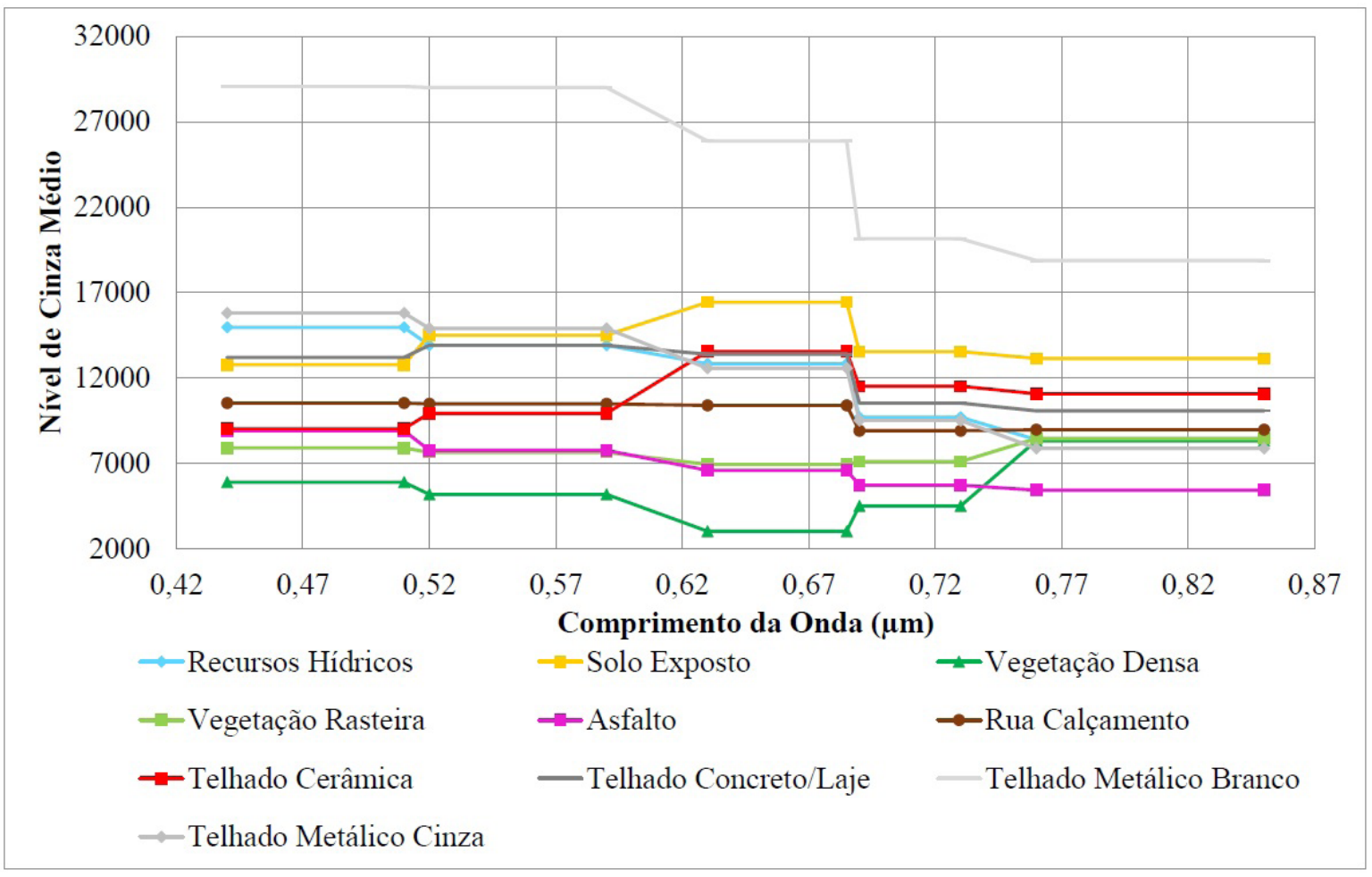

$\mathrm{Na}$ sequência foram executados os processamentos digitais de segmentação e classificação supervisionada. O processo de segmentação é recomendado quando a análise convencional por pixels gera limitações que são 
facilmente superadas pelos métodos de classificação digital supervisionada por regiões, nos quais se obtêm resultados visualmente consistentes e de fácil conversão em Sistemas de Informação Geográfica (SIG) (Espindola et al. 2006). No caso deste artigo, a alta resolução espacial e radiométrica das imagens é um bom indicativo para a escolha do método supervisionado por regiões.

O algoritmo de segmentação de imagens utilizado foi o de crescimento de regiões implementado no software SPRING, versão 5.3 (Câmara et al. 1996; Espindola et al. 2006). De acordo com Bins et al. (1996), trata-se de uma técnica de agrupamento de dados na qual somente as regiões adjacentes espacialmente podem ser agrupadas. Desta forma, os resultados obtidos dependem da escolha de parâmetros ajustados pelos usuários, que são os limiares de similaridade e de área (pixels). Após a realização de vários testes de segmentação pelo método de crescimento de regiões, aplicados considerando-se as cinco bandas espectrais das imagens RapidEye, foi selecionada para a etapa seguinte a imagem segmentada com limitar de similaridade de 850 e limitar de área de 90 .

Por fim, o algoritmo de classificação supervisionado por regiões utilizado foi o Bhattacharya, também implementado no software SPRING, versão 5.3 (Câmara et al. 1996). Tal classificador é recomendado para um processo baseado em regiões (resultantes da segmentação), com vistas a medir a separabilidade estatística das classes espectrais de interesse (Jensen 2007; Richards 2012). O algoritmo requer também a interação do usuário, por meio do treinamento e seleção de amostras das classes temáticas de interesse (Câmara et al. 1996). Como resultado desta etapa, obteve-se o mapa de uso do solo da mancha urbana de Teresina com as 10 classes temáticas identificadas.

\section{Mapas de Densidade: Áreas Construídas e População}

O artigo, além de fornecer um mapa dos usos urbanos da paisagem em Teresina, procura também investigar e construir mapas derivados destes usos. Isto porque, o importante nesta discussão é também mostrar que o crescimento de Teresina não tem sido acompanhado por uma distribuição equitativa dos investimentos em infraestrutura e do acesso da população aos serviços urbanos básicos, gerando desigualdades espaciais consideráveis. Para fins de comparação, é interessante distinguir duas partes principais da cidade de Teresina: uma relativa aos bairros mais centrais, e outra compreendendo o restante dos bairros, comumente denominada periferia. Neste estudo de caso, a periferia pode ser genericamente identificada como região distante do centro da cidade, onde a renda familiar das populações residentes é inferior à renda dos bairros centrais, e onde se encontram os piores níveis de serviços urbanos básicos.

Considerando-se que a segregação é um processo de organização do espaço caracterizado por áreas de forte homogeneidade social interna e de forte disparidade social entre elas, as áreas segregadas tendem a apresentar estruturas sociais que podem ser marcadas pela uniformidade da população com relação a alguns fatores (Kasy 2015; Smets e Salman 2015). Neste sentido, este artigo apresenta uma proposta metodológica para a espacialização da população na mancha urbana de Teresina, tornando possível uma visão não apenas estrutural da cidade, mas também uma visão sistêmica da segregação de suas áreas periféricas, considerando como fator de segregação a concentração populacional de famílias de baixa renda em áreas periféricas ou vulneráveis.

Tendo-se como base o mapa de uso do solo resultante da etapa anterior, foram gerados dois parâmetros espaciais de densidade urbana: (1) índice de densidade de áreas construídas, que varia entre 0 a 1; e (2) estimativa da distribuição espacial da população, tendo-se como base os dados de população do Censo Demográfico do 
IBGE de 2010 (IBGE 2013). Para o cálculo destes dois parâmetros foi selecionada a categoria temática de mancha urbana (Asfalto, Ruas/Calçamento e Telhados) do mapa de uso do solo. Posteriormente, a área de estudo foi então dividida em 31.664 células regulares com resolução de um hectare.

O (1) índice de densidade de áreas construídas foi calculado computando-se para cada célula do espaço celular a porcentagem de área coberta pela classe de mancha urbana, o que significa dizer que se o valor do índice for igual a 1, a célula estará 100\% coberta pela categoria de mancha urbana, se o valor do índice for igual a 0 , significa que a célula não possui interseção com esta categoria. Tal processamento foi realizado no software TerraView, versão 4.2 (Câmara et al. 2008), utilizando-se o pacote aRT do projeto estatístico R, versão 3.4 (Andrade e Ribeiro 2005; Gentleman et al. 2009; Espindola et al. 2012), e tendo-se como referência a metodologia descrita por Espindola et al. (2012). O resultado deste processo permite uma visão espacial sistemática da proporção, distribuição e contiguidade das áreas construídas da mancha urbana de Teresina.

Por usa vez, (2) a estimativa da distribuição espacial da população foi computada considerando-se do mapa de uso do solo apenas as classes temáticas relativas aos telhados (Cerâmico, Concreto/Laje, Metálico/ Cor Branca, Metálico/Cor Cinza). Estas classes foram selecionadas por serem elas as de maior associação e representação com moradias urbanas. Aqui também o processamento e agregação dos dados foram realizados conforme proposto por Espindola et al. (2012). Os dados originais da população foram obtidos do Censo Demográfico do IBGE do ano 2010, agregados nos setores censitários urbanos da cidade de Teresina (IBGE 2013). Os dados de população agregados pelos setores censitários foram então incorporados nas células por meio da ponderação do quantitativo da classe temática de telhados em cada célula, e a densidade populacional de cada setor censitário. Como resultado, cada célula da área de estudo possui uma estimativa de população, e como cada célula apresenta resolução de um hectare, os valores estimados nas células são representativos da densidade populacional destas.

\section{RESUltados E Discussão}

\section{Paisagem Urbana em Teresina}

A Figura 4 apresenta o mapa dos usos urbanos de Teresina resultante da classificação supervisionada das imagens RapidEye de 2011. A área de estudo encontra-se predominantemente ocupada por cobertura vegetal $(68,19 \%)$, seguida pela categoria de mancha urbana $(24,76 \%)$. Com menor participação na composição da paisagem urbana estão as categorias de solo exposto (4,97\%) e recursos hídricos (2,08\%). Com este mapeamento da ocupação urbana da cidade é possível detectar regiões mais críticas ao crescimento urbano, sendo possível uma percepção global da distribuição dos seus diversos usos. 
Figura 4 - Mapa dos usos urbanos da cidade de Teresina.

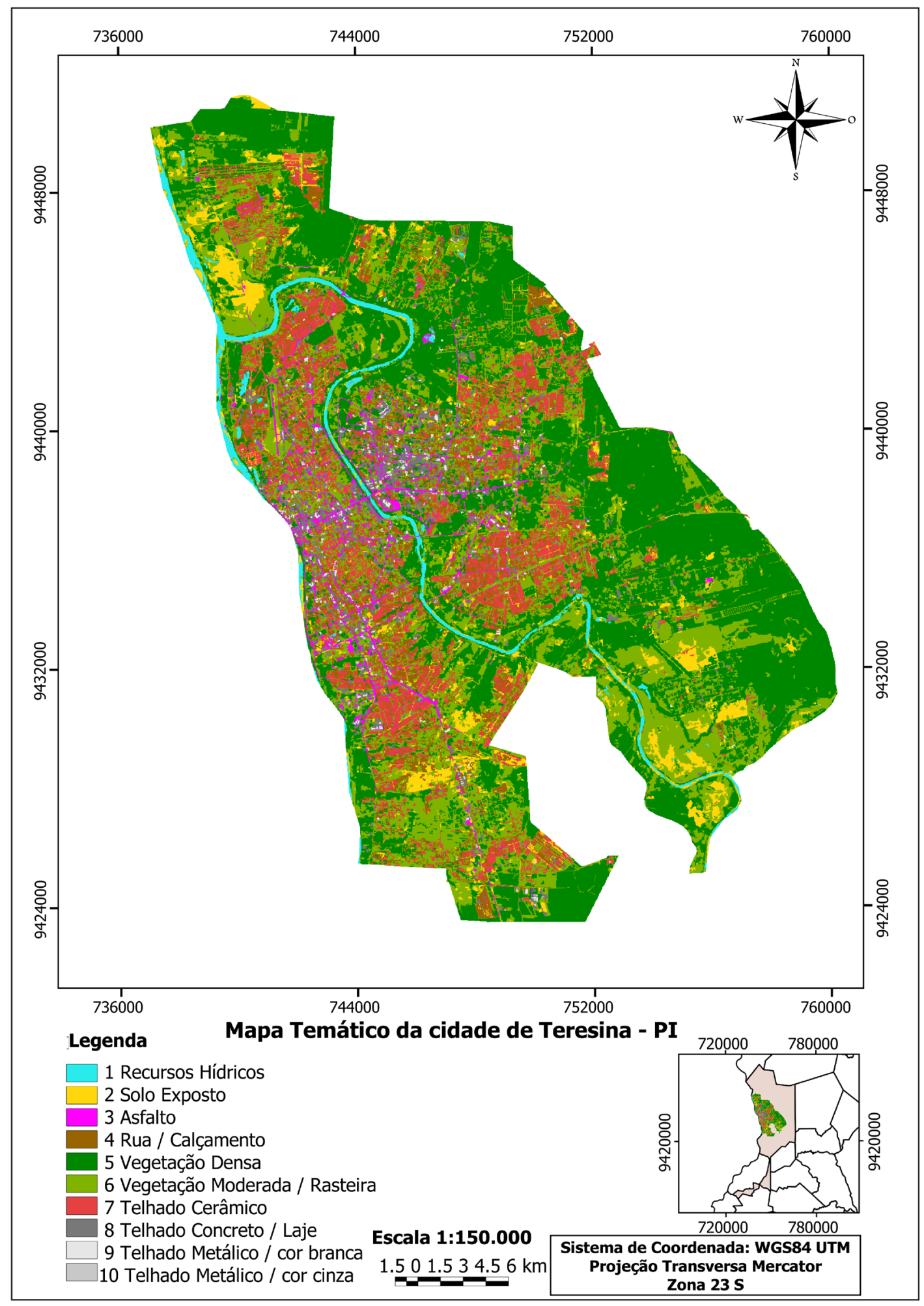

Nas Figuras 5a e 5b são apresentados os mapas do índice de densidade de áreas construídas e da estimativa da distribuição espacial da população, respectivamente. A análise conjunta destas duas figuras permite constatar que no perímetro urbano da cidade de Teresina existem áreas com altos índices de densidade de área construída, mas que não são efetivamente ocupadas, apresentando baixa densidade populacional. São estes os casos do bairro Centro e da porção central da zona Leste da cidade. Por outro lado, percebem-se áreas com altas densidades populacionais, principalmente na porção norte da zona Centro-Norte e nas zonas Sul e Sudeste. 
Figura 5 - Mapa do (a) índice de densidade de áreas construídas; e da (b) estimativa da distribuição espacial da população.

A

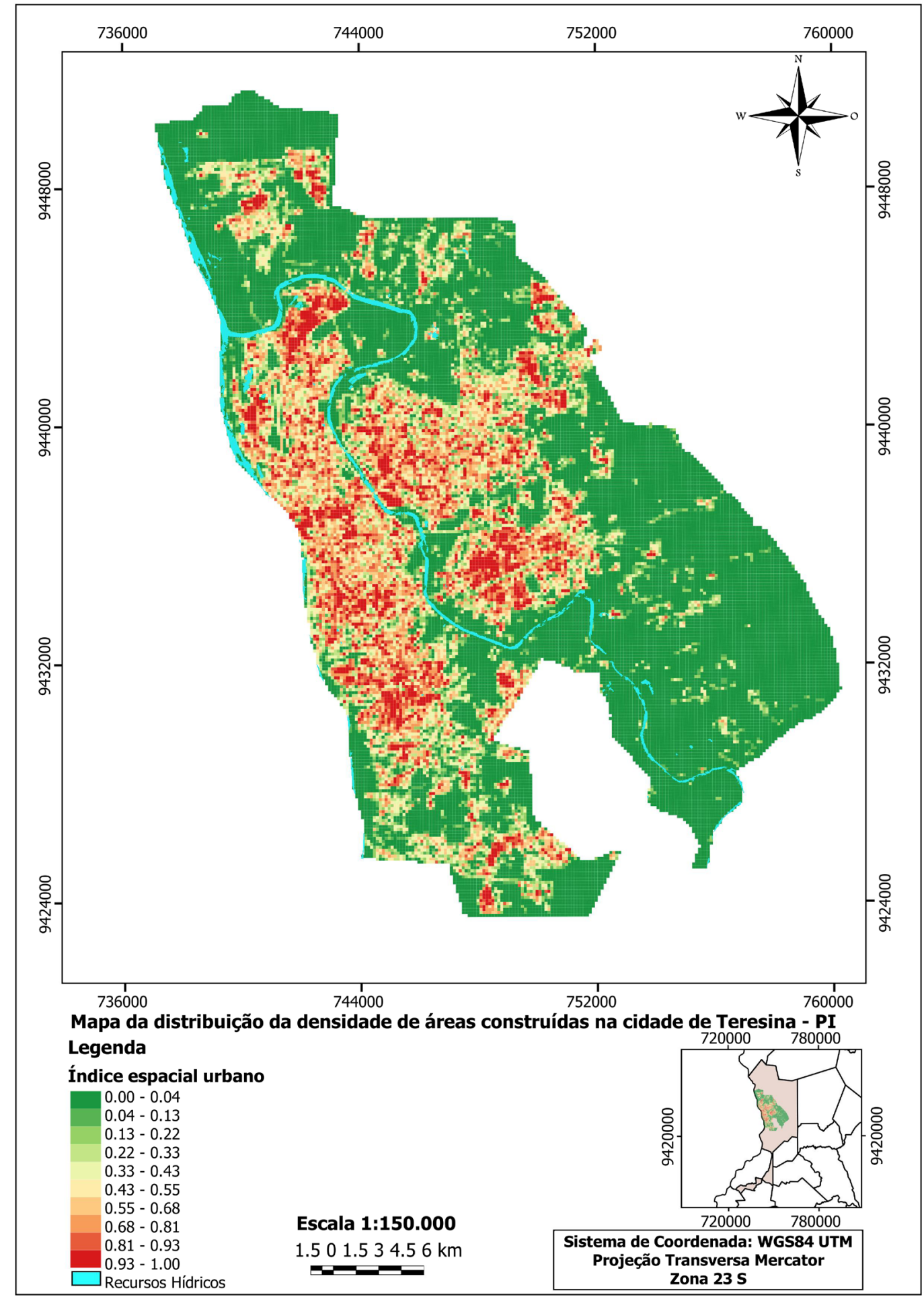


B

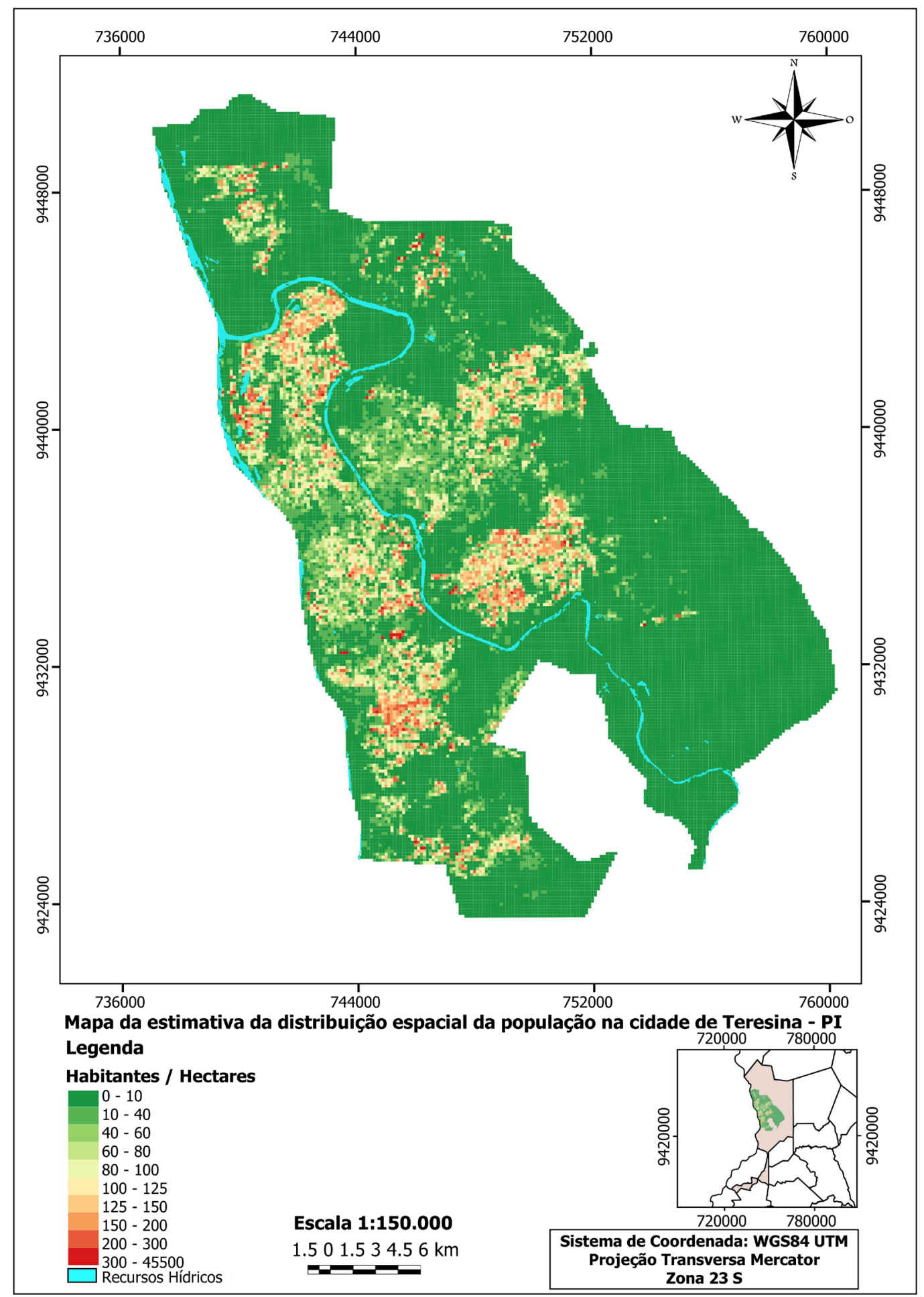

Neste artigo, parte-se do pressuposto de que esta situação é decorrente de um processo histórico de ocupação que desde a década de 1960 tem priorizado o assentamento de famílias de baixa renda em áreas periféricas por meio da implantação de Conjuntos Habitacionais construídos por programas do governo federal como a COHAB (Companhia de Habitação) e o Programa de Cidades de Porte Médio (Façanha 1998). Segundo Rodrigues et al. (2013), evidencia-se que, desde a década de 1960, a política habitacional em Teresina constituiuse como fator de relevância na descentralização da cidade. Na década seguinte, o I Plano Estrutural de Teresina (I PET) (Façanha e Silva Viana 2012) informava sobre considerável déficit habitacional na cidade, que viria a 
resultar na expansão das favelas em áreas irregulares ou de risco. Assim, este processo definiu, ao longo dos anos, o formato da cidade de Teresina por meio de um movimento em direção a periferia e da afirmação das tendências de crescimento urbano horizontal, principalmente na zona Sul, a partir da construção do Conjunto Parque Piauí em 1968.

Na década de 1990 houve uma redução nos investimentos em infraestrutura urbana e no setor habitacional por parte do governo federal, em parte motivado pelos baixos índices de crescimento econômico do país. Nesta década, com a redemocratização do país, tem-se a conciliação do planejamento urbano com a indução da Reforma Urbanística (Villaça 1999), com maior participação das camadas populares. Neste sentido, este processo representa um caráter mais prático de planejar a cidade para aqueles que dela usufrui.

Em Teresina, este processo coincidiu com o início da favelização da cidade, pois o movimento de pessoas em busca de moradia se manteve enquanto a oferta de habitações populares reduziu (Lima 2002; Façanha e Silva Viana 2012). É neste período também que se inicia o crescimento vertical da zona Leste, resultando no aparecimento de uma segregação espacial evidente. Ainda durante a década de 1990, a legislação urbana da cidade foi atualizada com alterações importantes e a incorporação de novos bairros ao seu perímetro urbano (Reis Filho e Moura 2014; Cruz et al. 2016).

Nos anos seguintes a 2000, os programas de habitações populares retornam, e a economia da cidade começa a chamar a atenção novamente da população rural, e de outros municípios que buscam na capital a oportunidade de sair do campo e obter melhores condições de moradia e estudo. Segundo Façanha (2003), o início deste período em Teresina foi marcado ainda pela criação das Superintendências de Desenvolvimento Urbano (SDU), nomeadas em Centro-Norte, Leste, Sudeste e Sul, e delimitadas segundo o atual perímetro urbano, estabelecido pela Lei $\mathrm{N}^{\circ}$ 3.559, de 20 de outubro de 2006. Assim, para Façanha (2005), esta descentralização administrativa acabou dificultando ainda mais a troca de informações entre a sociedade civil e os gestores públicos da cidade, tornando mais complicada a participação popular na construção de planos adequados às necessidades locais. Este maior excedente populacional acabou sendo marginalizado em áreas periféricas da cidade.

\section{Concentração Populacional em Áreas Periféricas}

Dentre os bairros mais populosos de Teresina serão analisados a seguir e com maior detalhe os bairros Dirceu Arcoverde na zona Sudeste e Mocambinho na zona Centro-Norte. Em 1977, a zona Sudeste recebeu a construção do maior conjunto habitacional da cidade, o conjunto Dirceu Arcoverde I. Em 1980, houve sua ampliação, com a criação do Dirceu Arcoverde II, ambos construídos pela COHAB (Façanha 2005). Atualmente, existem na região quatro grandes conjuntos habitacionais: Parque Itararé, Conjunto Dirceu Arcoverde I, Conjunto Dirceu Arcoverde II e Conjunto Parque Boa Esperança. Pela análise da Figura 6a observa-se que o bairro Dirceu Arcoverde apresenta como categoria majoritária de uso do solo a classe Telhado Cerâmico. O bairro apresenta também alto valor para o índice de densidade de áreas construídas, com valores variando entre 0,93 e 1,00 (Figura 6b), e alta concentração espacial da população, variando entre 100 a 200 habitantes/ ha (Figura 6c).

Seguindo tendência de ocupação semelhante, a zona Centro-Norte recebeu em 1982 a construção do conjunto José Francisco de Almeida Neto na zona Centro-Norte da cidade, que mais tarde se tornou o Bairro Mocambinho, e que atualmente engloba os conjuntos habitacionais Mocambinho I, Mocambinho II, 
Mocambinho III, Residencial Poty - Moca, Residencial São José e Conjunto Santa Sofia. Ao final da década de 1980, terras ao extremo norte da mancha urbana de Teresina são compradas pelo governo visando a implantação do polo industrial Companhia de Desenvolvimento Industrial do Piaú (CODIPI). Como tal iniciativa não foi implementada, famílias de baixa renda começaram a ocupar a região. Em 2009 foram iniciadas as obras do Conjunto Habitacional Jacinta Andrade com 4.300 unidades habitacionais, com verbas do Programa de Aceleração do Crescimento (PAC) do governo federal (Façanha e Silva Viana 2012; Rodrigues et al. 2013).

Figura 6 - Análise detalhada do bairro Dirceu Arcoverde na zona Sudeste de Teresina: (a) mapa dos usos urbanos; (b) mapa do índice de densidade de áreas construídas; e (c) mapa da estimativa da distribuição espacial da população.

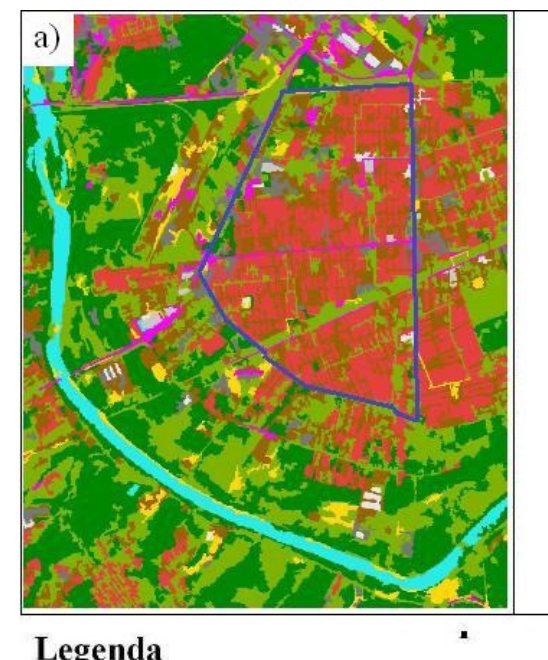

\section{Legenda}

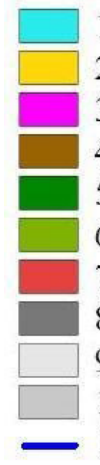

1 Recursos Hídricos

2 Solo Exposto

3 Asfalto

4 Rua / Calçamento

5 Vegetação Densa

6 Vegetação Moderada / Rasteira

7 Telhado Cerâmico

8 Telhado Concreto / Laje

9 Telhado Metálico / cor branca

10 Telhado Metálico / cor cinza

Limite - Bairro Dirceu Arcoverde

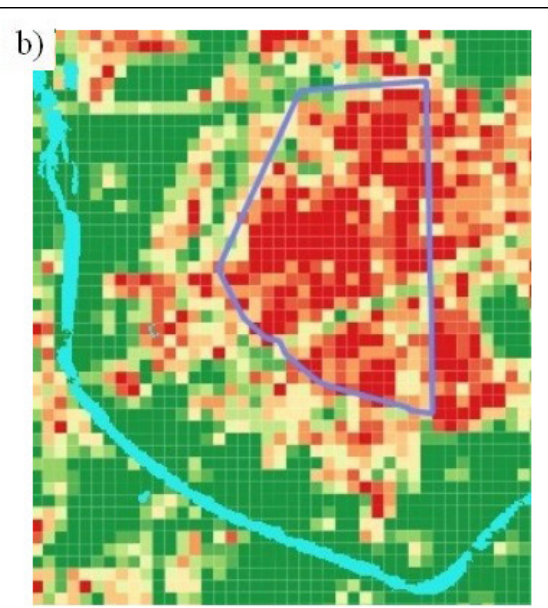

Legenda

Índice espacial urbano

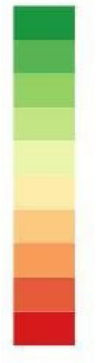

$0.00-0.04$

$0.04-0.13$

$0.13-0.22$

$0.22-0.33$

$0.33-0.43$

$0.43-0.55$

$0.55-0.68$

$0.68-0.81$

$0.81-0.93$

$0.93-1.00$

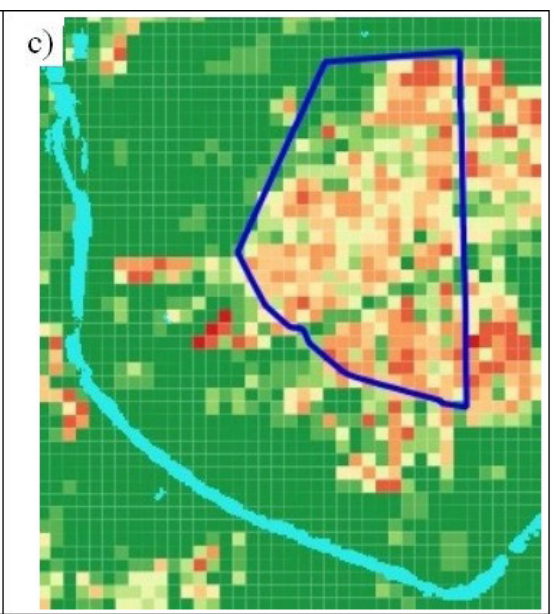

Legenda

Habitantes / Hectares

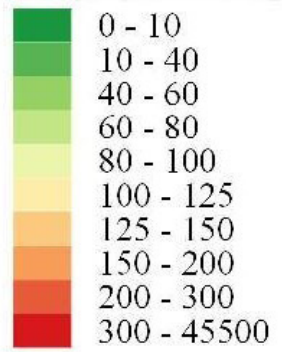

Pela análise da Figura 7a, observam-se semelhanças na cobertura majoritária de Telhado Cerâmico, e também alto valor para o índice de densidade de áreas construídas, com valores variando entre 0,93 e 1,00 (Figura 7b). A diferença entre o bairro Mocambinho e o Dirceu Arcoverde se dá em termos da densidade populacional, sendo a do primeiro um pouco mais baixa, com valores de concentração espacial da população variando entre 80 a 150 habitantes/hectares (Figura 7c). Em 2012, foi apresentado o Plano Local de Habitação de Interesse Social do município de Teresina (PLHIS), que tinha por objetivo diagnosticar a situação habitacional da capital e definir diretrizes de ação e intervenção (Rodrigues et al. 2013). Mesmo após este marco político, o crescimento da cidade continuou para além de seus limites urbanos, principalmente pela construção de conjuntos habitacionais e pela regularização fundiária de assentamentos precários (Façanha 2005). 
Vazio Populacional na Área Central

Num diferente contexto histórico de ocupação, encontra-se o bairro Centro, também localizado na zona Centro-Norte da cidade. Na Figura 8a é possível constatar a diferença da cobertura majoritária, que neste caso é de Asfalto, Telhado Concreto/Laje e Telhado Metálico/Cor Cinza, caracterizando a área como preferencialmente comercial. As diferenças continuam, e apesar de o bairro também apresentar alto valor para o índice de densidade de áreas construídas, com valores variando entre 0,93 e 1,00 (Figura 8b), o mesmo apresenta valores bem baixos de concentração espacial da população, variando entre 0 a 60 habitantes/ha (Figura 8c).

Figura 7 - Análise detalhada do bairro Mocambinho na zona Centro-Norte de Teresina: (a) mapa dos usos urbanos; (b) mapa do índice de densidade de áreas construídas; e (c) mapa da estimativa da distribuição espacial da população.

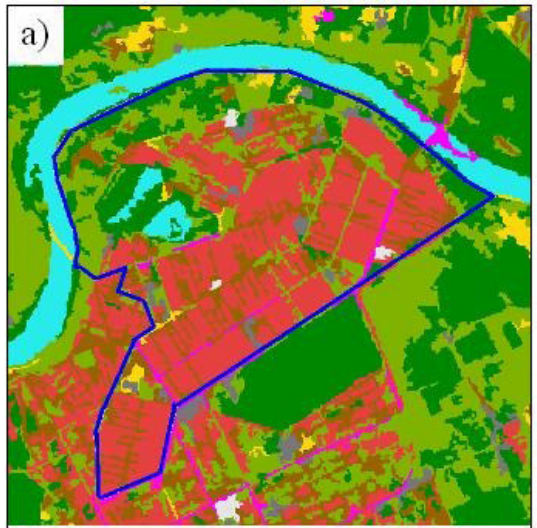

Legenda

\begin{tabular}{l}
\hline 1 Recursos Hídricos \\
2 Solo Exposto \\
3 Asfalto \\
4 Rua / Calçamento \\
5 Vegetação Densa \\
6 Vegetação Moderada / Rasteira \\
7 Telhado Cerâmico \\
8 Telhado Concreto / Laje \\
9 Telhado Metálico / cor branca \\
10 Telhado Metálico / cor cinza \\
\hline$\square$
\end{tabular}

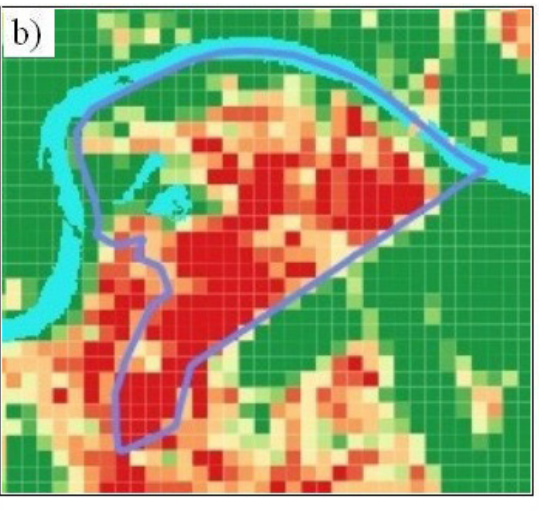

Legenda

Índice espacial urbano

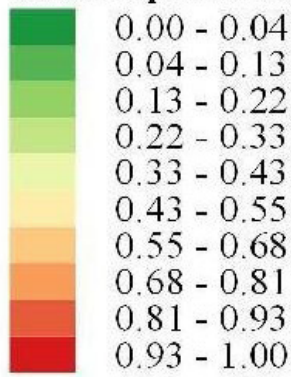

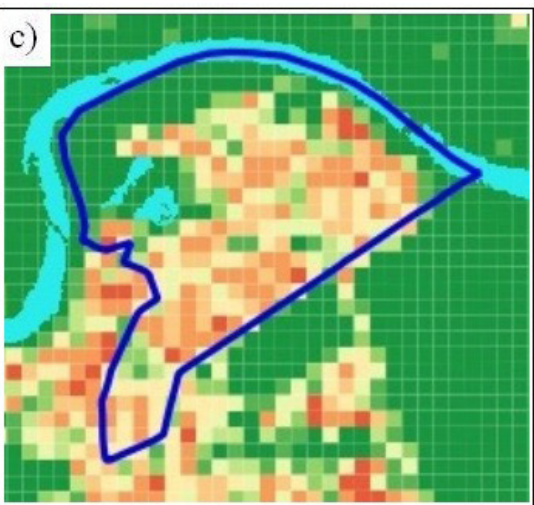

Legenda

Habitantes / Hectares

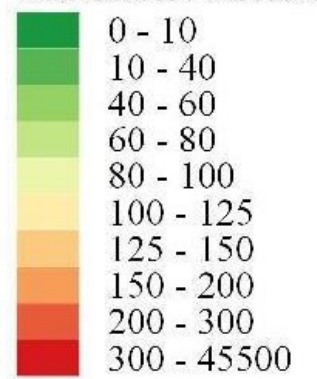

- Limite - Bairro Dirceu Arcoverde

Por fim, confrontando-se os resultados obtidos para os três bairros analisados e também considerando a cidade em sua totalidade, verifica-se que, apesar de numa análise baseada nos bairros a média os valores máximos de densidade populacional estarem próximos ao padrão de 100 habitantes/ha estabelecido pela legislação municipal, a realidade, quando vista mais pontualmente é diferente, pois a densidade populacional urbana da cidade varia consideravelmente, concentrando maiores valores em áreas periféricas em assentamento populacional de baixa renda, onde os níveis de densidade populacional estimados estão bem acima da média dos padrões estabelecidos.

Assim, a situação da progressiva expansão urbana de Teresina registra, após os anos 2000, um expressivo aumento populacional, que ocorreu em todas as direções (Façanha e Silva Viana 2012; Rodrigues et al. 2013; Espindola et al. 2017). Consideráveis investimentos do Governo Federal contribuíram de forma significativa no 
padrão de crescimento periférico da cidade, negligenciando ações de fixação da população em áreas urbanas consolidadas. Constata-se assim, que a evolução urbana da capital do Piaú apresenta em sua fase atual um alargamento urbano com profundas desigualdades e falta de infraestrutura urbana básica.

Figura 8 - Análise detalhada do bairro Centro na zona Centro-Norte de Teresina: (a) mapa dos usos urbanos; (b) mapa do índice de densidade de áreas construídas; e (c) mapa da estimativa da distribuição espacial da população.

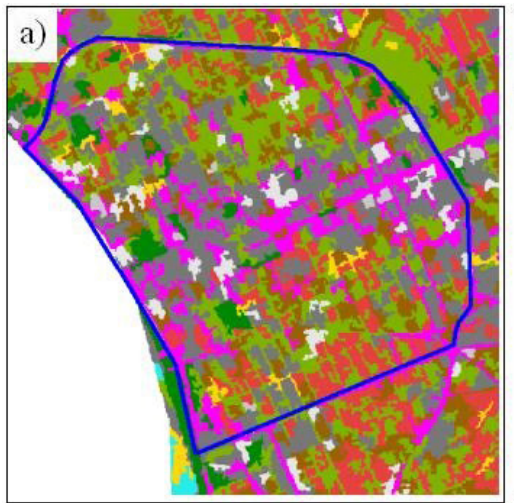

Legenda

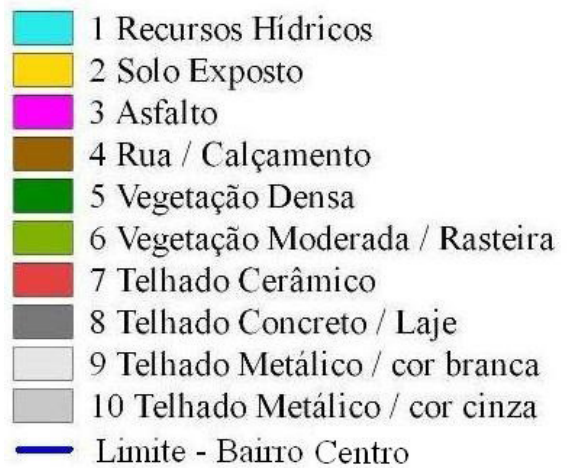

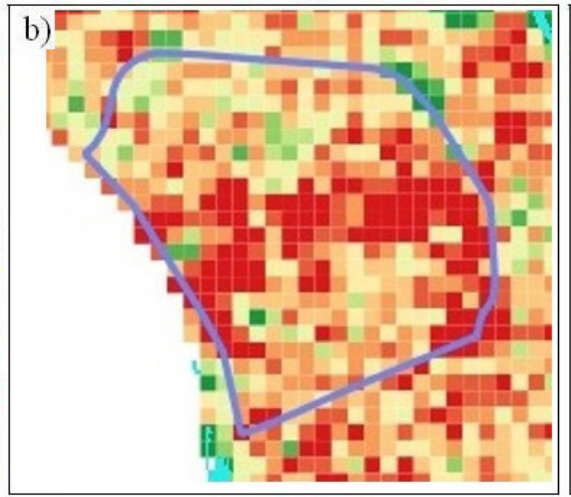

Legenda

Índice espacial urbano

$0.00-0.04$

$0.04-0.13$

$0.13-0.22$

$0.22-0.33$

$0.33-0.43$

$0.43-0.55$

$0.55-0.68$

$0.68-0.81$

$0.81-0.93$

$0.93-1.00$

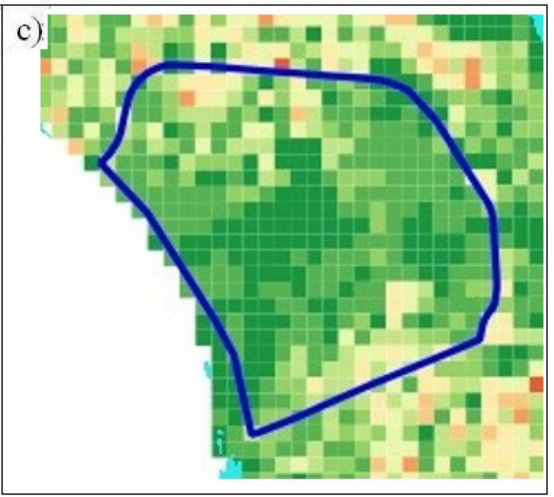

Legenda

Habitantes / Hectares

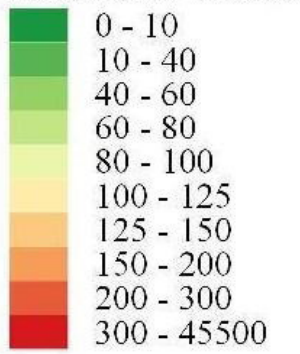

\section{Conclusão}

No início do processo de urbanização, Teresina foi construída principalmente ao longo de áreas ao redor do centro e próximas ao leito do Rio Parnaíba. A expansão nos sentidos Norte, Sul e Leste se deu até meados da década de 1970 de forma radial, quando então se iniciaram as construções de conjuntos habitacionais em áreas periféricas e desconectadas da malha urbana, destinados prioritariamente para acomodar a população de baixa renda que chegava a cidade em frentes migratórias contínuas. Tais conjuntos foram localizados em regiões distantes, que ainda hoje sofrem com problemas de acesso aos serviços urbanos básicos de saneamento e transporte.

Os resultados do artigo mostram que grande parte da população da cidade encontra-se instalada em áreas periféricas, o que tem contribuído para a marginalização desta população. Por outro lado, a distribuição espacial da densidade urbana na cidade também varia consideravelmente, e tem desafiado os planos de um desenvolvendo mais sustentável para a cidade e sua população. Mesmo a legislação municipal tratando de padrões de densidade urbana por zonas da cidade, os mapas apresentados mostram que os valores de densidade variam localmente, tornando necessária uma discussão mais ampla e abrangente sobre o futuro da cidade.

Além disso, as tendências de urbanização de Teresina indicam que a expansão urbana sem um necessário 
planejamento tem criado problemas relacionados com a ocupação de importantes áreas de sistemas ambientais. Desenvolvimento urbano sustentável é uma meta difícil de ser alcançada por municípios com baixo desenvolvimento econômico. Depois de décadas de produção do espaço urbano com pouca preocupação sobre seus recursos naturais, é ainda mais difícil reorganizar as áreas urbanizadas para manter o valor das condições ambientais. É um desafio constante acomodar um contingente crescente da população urbana, suprindo as infraestruturas e serviços públicos, e ainda perseguindo uma qualidade ambiental por meio de uma densidade que dê suporte aos ideais de qualidade e sustentabilidade.

Os resultados do artigo mostram ainda uma ocupação intensa em regiões susceptíveis a enchentes na confluência dos rios Parnaíba e Poti. Vastas áreas foram continuamente desmatadas para loteamentos irregulares, particularmente em relevo íngreme, sem considerar a inclinação, os fluxos de água naturais e contenção adequada para a erosão. Com base nessas conclusões, faz-se necessário expor algumas recomendações relativas aos programas de habitação e de infraestrutura urbana que deverão nortear uma discussão mais abrangente sobre o futuro da cidade. Tais recomendações são:

1. Os programas habitacionais devem priorizar locais com infraestrutura já disponível, principalmente com relação as redes de transporte e de saneamento; e também modelo vertical das habitações.

2. Ações do governo municipal devem priorizar a reocupação residencial no centro comercial da cidade, viabilizando uma utilização eficiente de uma infraestrutura já implantada, assim como, priorizar a integração urbanística das áreas habitadas e mais populosas da cidade.

3. No âmbito ambiental, as ações do governo devem priorizar o remanejamento de domicílios localizados em áreas de risco ambiental em toda a extensão dos Rios Parnaíba e Poti e em áreas susceptíveis a enchentes.

\section{REFERÊNCIAS}

Andrade P, Ribeiro P. 2005. Integration of statistics and geographic information systems: the R/Terralib case. VII Brazilian Symposium on Geoinformatics, Campos do Jordão: Brazil.

Antunes M, Debiasi P, Santos Siqueira J. 2014. Avaliação espectral e geométrica das imagens RapidEye e seu potencial para o mapeamento e monitoramento agrícola e ambiental. Revista Brasileira de Cartografia, 1 (66):34-58.

Bartholomé E, Belward A. 2005. GLC2000: a new approach to global land cover mapping from earth observation data. International Journal of Remote Sensing, 26 (9):1959-1977.

Bartholomé E, Belward A, Achard F, Bartalev S, Carmona-Moreno C, Eva H, Fritz S, Grégoire J, Mayaux P, Stibig H. 2002. GLC 2000: global land cover mapping for the year 2000: project status november 2002. Institute for Environment and Sustainability, 1 (1):1-10.

Bertrand G. 2004. Paisagem e geografia física global. Esboço metodológico. Raega-O Espaço Geográfico em Análise, 8 (1):45-79.

Bins L, Fonseca L, Erthal G, Ii F. 1996. Satellite imagery segmentation: a region growing approach. Simpósio Brasileiro de Sensoriamento Remoto, 8 (1996):677-680. 
Boshuizen C, Mason J, Klupar P, Spanhake S. 2014. Results from the planet labs flock RapidEye constellation. RapidEye Magazine, 1 (1):10-23.

Brenner N, Schmid C. 2014. The 'urban age' in question. International Journal of Urban and Regional Research, 38 (3):731-755.

Buhaug H, Urdal H. 2013. An urbanization bomb? Population growth and social disorder in cities. Global Environmental Change, 23 (1):1-10.

Burrough PA, McDonnell RA. 1998. Principles of GIS. Vol. 1. London: Oxford University Press.

Câmara G, Souza RCM, Freitas UM, Garrido J. 1996. SPRING: Integrating remote sensing and GIS by objectoriented data modelling. Computers \& graphics, 20 (3):395-403.

Câmara G, Vinhas L, Ferreira KR, Queiroz GR, Souza RCM, Monteiro AMV, Carvalho MT, Casanova MA, Freitas UM. 2008. Terralib: an open source gis library for large-scale environmental and socio-economic applications. In Open source approaches in spatial data handling, 247-270.

Cruz ICS, Espindola GM, Carneiro ELNC. 2016. Três décadas de expansão urbana e concentração populacional em Teresina, Piauí, Brasil. Espacios (Caracas), 37 (24).

Damiani AL. 2004. Urbanização crítica e situação geográfica a partir da metrópole de São Paulo. Geografias de São Paulo, 1:19-58.

Duque JC, Patino JE, Ruiz LA, Pardo-Pascual JE. 2015. Measuring intra-urban poverty using land cover and texture metrics derived from remote sensing data. Landscape and Urban Planning, 135:11-21.

Espindola GM, Aguiar APD, Andrade PR. 2012. Combining satellite remote sensing and census data to quantify agricultural land use change in the Brazilian Amanzon. Revista Brasileira de Cartografia, 63 (3):56-88.

Espindola GM, Camara G, Reis IA, Bins LS, Monteiro AM. 2006. Parameter selection for region-growing image segmentation algorithms using spatial autocorrelation. International Journal of Remote Sensing, 27 (14):3035-3040.

Espindola GM, Carneiro ELNC, Façanha AC. 2017. Four decades of urban sprawl and population growth in Teresina, Brazil. Applied Geography, 79 (1):73-83.

Façanha AC. 1998. A evolução urbana de Teresina: agentes, processos e formas espaciais da cidade. Dissertação. Mestrado em Geografia, Universidade Federal de Pernambuco.

Façanha AC. 2003. A evolução urbana de Teresina: passado, presente e futuro. Carta Cepro, 22 (1):59-69.

Façanha AC. 2005. Gestão urbana e dilemas no poder local: internidade e dispersão em Teresina (PI). Revista de Geografia (Recife), 24 (1):77-97.

Façanha AC, Silva Viana BA. 2012. Planejamento e gestão urbana em Teresina (PI): notas da agenda 2015 como plano diretor. Revista Equador, 1 (1):60-78. 
Felix IM, Kazmierczak ML, Espindola GM. 2009. Rapideye: a nova geração de satélites de observação da terra. Anais XIV Simpósio Brasileiro de Sensoriamento Remoto:7619-7622.

Ferreira A. 2007. A produção do espaço: entre dominação e apropriação. Um olhar sobre os movimentos sociais. Scripta Nova. Revista Electrónica de Geografía y Ciencias Sociales. Barcelona: Universidad de Barcelona, 11 (245):15.

Gentleman R, Ihaka R, Bates D. 2009. The R project for statistical computing. R Project Website.

Güneralp B, Seto KC, Ramachandran M. 2013. Evidence of urban land teleconnections and impacts on hinterlands. Current Opinion in Environmental Sustainability, 5 (5):445-451.

IBGE. 2013. Censo Demográfico 2010. In: Síntese de Indicadores. Rio de Janeiro: IBGE.

Jensen JR. 2007. Remote sensing of the environment: an earth resource perspective: Pearson Prentice Hall.

Kasy M. 2015. Identification in a model of sorting with social externalities and the causes of urban segregation. Journal of Urban Economics, 85:16-33.

Landau EC, Cruz R, Hirsch A, Pimenta FM, Guimarães DP. 2012. Variação geográfica do tamanho dos módulos fiscais no Brasil. Empresa Brasileira de Pesquisa Agropecuária:1518-4277.

Leite ME, Rosa R. 2006. Geografia e geotecnologias no estudo urbano. Caminhos de Geografia, 7 (17).

Li X, Gong P, Liang L. 2015. A 30-year (1984-2013) record of annual urban dynamics of Beijing City derived from Landsat data. Remote Sensing of Environment, 166:78-90.

Lima I. 2002. Teresina: urbanização e meio ambiente. Scientia et Spes: Revista do Instituto Camilo Filho, 1 (02):181-206.

Limoeiro D. 2015. Beyond income transfers: the decline of regional inequality in brazil during the 2000s. Progress in Development Studies, 15 (1):6-21.

MacLachlan A, Biggs E, Roberts G, Boruff B. 2017. Urban growth dynamics in Perth, Western Australia: using applied remote sensing for sustainable future planning. Land, 6 (1):9.

Marandola Jr E, Modesto F. 2012. Perception of urban environmental threats and place effects on the populationenvironment relationship. Revista Brasileira de Estudos de População, 29 (1):7-35.

Maurício P, Barros MVF. 2012. Urban sprawl and the challenges for urban planning. Journal of Environmental Protection, 2012.

Nogueira LLF, Espindola GM, Carneiro ELNC. 2016. Análise da ocupação urbana na zona Centro-Norte de Teresina: considerações sobre a região do Encontro dos Rios. Revista Equador, 5 (3):25-42.

Pereira GC, Silva BCN. 2001. Geoprocessamento e urbanismo. Revista de Universidade Federal da Bahia, 
$1(1)$.

Reis Filho AAd, Moura AC. 2014. Contribuição do geoprocessamento para o estatuto da cidade como ferramenta para o planejamento e gestão urbana. Seminario Internacional de Investigación en Urbanismo, Barcelona, Bogotá.

Richards JA. 2012. Remote sensing digital image analysis: an introduction. Vol. 1. New Yourk: Springer.

Rodrigues RS, Cardoso JA, Carneiro WP. 2013. Planejamento urbano em Teresina: análise das projeções de expansão urbana. Revista Equador, 2 (1):160-162.

Rodrigues RS, Veloso Filho FA. 2013. O planejamento urbano no Brasil: trajetória e perspectivas atuais. X Encontro Nacional da Associação de pós-Graduação e Pesquisa em Geografia, Campinas.

Seto KC, Reenberg A, Boone CG, Fragkias M, Haase D, Langanke T, Marcotullio P, Munroe DK, Olah B, Simon D. 2012. Urban land teleconnections and sustainability. Proceedings of the National Academy of Sciences, 109 (20):7687-7692.

Slocum TA. 2009. Thematic cartography and geovisualization. Vol. 1. New York: Prentice Hall.

Smets P, Salman T. 2015. The multi-layered-ness of urban segregation: on the simultaneous inclusion and exclusion in latin american cities. Habitat International.

Sperandelli DI, Dupas FA, Dias Pons NA. 2013. Dynamics of urban sprawl, vacant land, and green spaces on the metropolitan fringe of são paulo, brazil. Journal of Urban Planning and Development, 139 (4):274-279.

Stoll E, Shahid K, Paasche E, Apel M. 2014. The sustainability of the RapidEye remote sensing constellation. Small Satellite Systems and Services Symposium, Mallorca, Spain.

Turner BL, Lambin EF, Reenberg A. 2007. The emergence of land change science for global environmental change and sustainability. Proceedings of the National Academy of Sciences, 104 (52):20666-20671.

Tyner JA. 1992. Introduction to thematic cartography: Prentice Hall Englewood Cliffs, NJ.

United Nations. 2014. World urbanization prospects: the 2014 revision, highlights Vol. 1. New York: ONU. van Rees E. 2014. Delivering the world Blackbridge. GeoInformatics, 17 (3):18.

Villaça F. 1999. Uma contribuição para a história do planejamento urbano no Brasil. O processo de urbanização no Brasil. São Paulo: Edusp.

Wang H, He Q, Liu X, Zhuang Y, Hong S. 2012. Global urbanization research from 1991 to 2009: a systematic research review. Landscape and Urban Planning, 104 (3):299-309. 